Recebido em: 3 Set. 2019

Aprovado em: 9 Nov. 2019

Publicado em: 8 Dez. 2019

\title{
ANÁLISE DE CONTEÚDO: PROPOSTA CURRICULAR DE SANTA CATARINA NA PERSPECTIVA DA EDUCAÇÃO EM DIREITOS HUMANOS
}

\author{
CONTENT ANALYSIS: SANTA CATARINA'S CURRICULUM PROPOSAL FOR A HUMAN \\ RIGHTS EDUCATION PERSPECTIVE \\ ANÁLISIS DE CONTENIDO: PROPUESTA DE CURRÍCULO DE SANTA CATARINA PARA \\ UNA PERSPECTIVA DE EDUCACIÓN EN DERECHOS HUMANOS
}

Simone Schelbauer Moreira Paes Pontifícia Universidade Católica do Paraná

E-mail: simonepaes6@gmail.com

Sabrina Moreira Paes Universidade Estadual de Campinas E-mail: sabrinapaes22@gmail.com

Mirian Célia Castellain Guebert Pontifícia Universidade Católica do Paraná

RESUMO E-mail: mirian.castellain@pucpr.br

A Declaração Universal de Direitos Humanos (DUDH) é documento que preza pela igualdade, o respeito às diversidades, a paz entre as nações, democratização e relevância da educação para a sociedade. A Educação na temática dos Direitos Humanos é considerada relevante e necessária nas redes de ensino. A promulgação das Diretrizes Nacionais para a Educação em Direitos Humanos (DNEDH), por meio da Resolução $n^{\circ} 1$, de 30 de maio de 2012 organiza os processos educativos. O estado de Santa Catarina incluiu a Educação em Direitos Humanos na Proposta Curricular de 2014, sem referenciar as Diretrizes Nacionais. A ausência de tal menção definiu o objetivo deste trabalho que seria analisar de que forma a Proposta Curricular de Santa Catarina (PCSC) de 2014 contempla a Educação em Direitos Humanos. A metodologia utilizada foi a análise de conteúdo de Bardin. Os resultados obtidos foram baseados nos doze artigos considerados da DNEDH, sendo que nove estão contemplados na PCSC, totalizando $75 \%$ da implementação do que prevê a resolução $01 / 12$. Contudo, a proposta está orientada por outros documentos nacionais que visam incluir uma Educação em Direitos Humanos, além de assegurar o direito de todos à educação e atender a diversidade da clientela contemporânea.

PALAVRAS-CHAVE: Direitos Humanos e Educação. Proposta Curricular. Análise de Conteúdo

\section{ABSTRACT}

The Universal Declaration of Human Rights (UDHR) is a document that values equality, respect for diversity, peace among nations, democratization and the relevance of education to society. Human rights education is considered relevant and necessary in educational networks. The promulgation of the National Guidelines for Human Rights Education (DNEDH), through Resolution No. 1 of May 30, 2012 organizes the educational processes. The state of Santa Catarina included Human Rights Education in its 2014 Curriculum Proposal, without reference to the National Guidelines. The absence of such mention defined the purpose of this paper which would be to analyze how the 2014 Santa Catarina Curriculum Proposal (PCSC) contemplates Human Rights Education. The methodology used was Bardin content analysis. The results obtained were based on the twelve articles considered by the DNEDH, nine of which are included in the PCSC, totaling $75 \%$ of the implementation of which Resolution 01/12 provides. However, the proposal is guided by other national documents aimed at including Human Rights Education, as well as ensuring everyone's right to education and addressing the diversity of contemporary clientele.

KEYWORDS: Human Rights and Education. Curriculum Proposal.Content Analysis. 


\section{RESUMEM}

La Declaración Universal de Derechos Humanos (DUDH) es un documento que valora la igualdad, el respeto a la diversidad, la paz entre las naciones, la democratización y la relevancia de la educación para la sociedad. La educación en derechos humanos se considera relevante y necesaria en las redes educativas. La promulgación de las Directrices Nacionales para la Educación en Derechos Humanos (DNEDH), mediante la Resolución $N^{\circ} 1$ del 30 de mayo de 2012, organiza los procesos educativos. El estado de Santa Catarina incluyó la Educación en Derechos Humanos en su Propuesta Curricular 2014, sin referencia a las Directrices Nacionales. La ausencia de dicha mención definió el propósito de este documento, que sería analizar cómo la Propuesta Curricular de Santa Catarina (PCSC) 2014 contempla la Educación en Derechos Humanos. La metodología utilizada fue el análisis de contenido de Bardin. Los resultados obtenidos se basaron en los doce artículos considerados por el DNEDH, nueve de los cuales están incluidos en el PCSC, totalizando el $75 \%$ de la implementación que establece la Resolución 01/12. Sin embargo, la propuesta se guía por otros documentos nacionales destinados a incluir la educación en derechos humanos, así como a garantizar el derecho de todos a la educación y abordar la diversidad de la clientela contemporánea.

PALABRAS CLAVE: Derechos humanos y Educación. Propuesta Curricular. Análisis de Contenido.

\section{INTRODUÇÃO}

A sociedade moderna e global do século XXI é regida por diversos princípios e leis conquistados ao longo da história. Em 1948 iniciou-se uma nova era para a humanidade com a assinatura da Declaração Universal dos Direitos Humanos (DUDH), por meio da qual “[...] pela primeira vez um sistema de princípios fundamentais de conduta humana foi livre e expressamente aceito, através de seus respectivos governos, pela maioria dos homens que vive na terra". (BOBBIO, 1992, p. 28). A partir desta nova ideologia, os direitos humanos foram sendo incorporados dentro da sociedade nas mais distintas áreas até sua chegada ao âmbito educacional, fato que no Brasil ocorreu tardiamente com a consolidação da declaração somente em 1980 (TOSI, 2010) e posterior criação do Plano Nacional de Educação em Direitos Humanos (PNEDH) em 2003 (BRASIL, 2006).

A fim de obter um aprofundamento e maior consolidação quanto à aplicação dos Direitos Humanos dentro do sistema educacional brasileiro, foi criado em 2003, o Plano Nacional de Educação em Direitos Humanos (PNEDH) contemplando dois objetivos principais: consolidar "[...] uma proposta de um projeto de sociedade baseada nos princípios da democracia, cidadania e justiça social [...]" e reforçar “[...] um instrumento de construção de uma cultura de direitos humanos, entendida como um processo a ser apreendido e vivenciado na perspectiva da cidadania ativa". (BRASIL, 2006, p. 11). O PNEDH afirma a compreensão e aplicação nacional da Educação em Direitos Humanos tendo em vista a formação de sujeitos de direitos em consonância com a consolidação de atitudes, princípios e práticas do cidadão no âmbito de direitos e deveres intrínsecos a ele, a elaboração de novos 
métodos de ensino flexíveis e participativos, o incentivo a iniciativas em defesa e promoção dos Direitos Humanos e a geração de uma percepção cidadã mais ampla. (FORTES, 2010).

A incorporação do novo modelo de educação a nível nacional, baseado em Direitos Humanos, abrange as esferas de ensino básico e superior promovendo intervenções positivas nas Propostas Curriculares devido à criação das Diretrizes Nacionais para a Educação em Direitos Humanos. (CANDAU, 2006). Segundo o Artigo $7^{\circ}$ dessas Diretrizes, a organização das esferas de abrangência, básica e superior, deve ser respaldada na transversalidade, a qual se traduz em uma abordagem ampla e interdisciplinar dos Direitos Humanos, em contraposição aos sistemas educacionais remotos e limitados. (BRASIL, 2012a).

Embora a Educação em Direitos Humanos seja preconizada pelo PNEDH e resoluções associadas, algumas Propostas Curriculares Estaduais podem não atender na íntegra aos requisitos estabelecidos, como é o caso de Santa Catarina. Com base nessa premissa, o objetivo deste trabalho foi analisar de que forma a Proposta Curricular de Santa Catarina (2014) contempla a Educação em Direitos Humanos.

\section{REFERENCIAL TEÓRICO}

A humanidade nunca esteve tão respaldada em princípios organizativos e valores como agora. Este cenário contemporâneo ganha forma com a criação da Declaração Universal dos Direitos Humanos (DUDH) em 1948 e o consequente estabelecimento dos direitos e deveres de todo e qualquer ser humano. Tal documento é tido como um "ideal comum a atingir por todos os povos e todas as nações, a fim de que todos os indivíduos e todos os órgãos da sociedade, [...] se esforcem, pelo ensino e pela educação”. (UN, 1948, p. 1).

De forma sucinta, os Direitos Humanos podem ser definidos como um "[...] conjunto de direitos civis, políticos, sociais, econômicos, culturais e ambientais, sejam eles individuais, coletivos, transindividuais ou difusos, referem-se à necessidade de igualdade e de defesa da dignidade humana" (BRASIL, 2012a, p. 1)

\subsection{Educação em direitos humanos}

O vocábulo Educação em Direitos Humanos, segundo o PNEDH, pode ser definido como

um processo sistemático e multidimensional que orienta a formação dos sujeitos de direitos, articulando as seguintes dimensões: a) apreensão de conhecimentos historicamente construídos sobre direitos humanos e a sua relação com os contextos internacional, nacional e local; b) afirmação de 
valores, atitudes e práticas sociais que expressem a cultura dos direitos humanos em todos os espaços da sociedade; c) formação de uma consciência cidadã capaz de se fazer presente em níveis cognitivo, social, ético e político; d) desenvolvimento de processos metodológicos participativos e de construção coletiva, utilizando linguagens e materiais didáticos contextualizados; e) fortalecimento de práticas individuais e sociais que gerem ações e instrumentos a favor da promoção, da proteção e da defesa dos direitos humanos, bem como da reparação das violações (BRASIL, 2006, p. 3).

Nesse contexto, percebe-se que a educação é um instrumento que pode possibilitar a efetivação dos direitos humanos, de forma organizada, por meio do diálogo no falar e ouvir o outro. Ela assume um papel fundamental quanto ao exercício dos direitos humanos, tendo em vista o espaço privilegiado para construção de conhecimentos, agregação de valores e formação da cidadania, adotando como referência a vivência desses direitos de forma plena e integral por parte da instituição e de todos os envolvidos em seu funcionamento. (BRASIL, 2012b). Dentro deste ambiente, a Educação em Direitos Humanos deve ser exercida visando a construção de sujeitos de direitos e, futuramente, uma cultura informal de direitos, conforme estabelecido nas Diretrizes Nacionais para a Educação em Direitos Humanos. (BRASIL, 2012a).

Sob essa ótica, os Direitos Humanos devem ser abordados respeitando a individualidade das distintas fases do desenvolvimento presentes na escola, afinal eles constituem "[...] uma área do conhecimento transdisciplinar que deve estar presente na formação de todas e todos desde a mais tenra idade, alcançando, inclusive, a formação inicial [...]”. (FORTES, 2010, p. 9). Contudo, o ensino na educação básica deve ser voltado à compreensão de que o ser humano é incompleto e necessita de constante renovação dos conhecimentos, bem como o desenvolvimento de valores e comportamentos em consonância com o atual momento da sociedade. (SILVA, 2010).

A Educação em Direitos Humanos traz consigo a função de compreensão do significado de ser humano, da relação entre o ensino como um direito implícito e o ensino dos direitos humanos, da consolidação desses direitos na sociedade e da construção de uma consciência cidadã, a fim de democratizar a sociedade e estabelecer uma cultura de direitos humanos que abranja o contexto informal. (CANDAU, 2006). O objetivo dessa cultura em Direitos Humanos seria construir "uma cultura centrada no convívio plural e na aceitação da diversidade, no respeito à dignidade da pessoa humana e na preocupação com a justiça social" (BITTAR, 2008, p. 319) fundamentada nos produtos informais gerados por meio da comunicação a partir da educação formal fornecida no ensino básico nas escolas. (TAVARES 
et al, 2010). O que se busca com tudo isso, é a construção em massa de uma consciência cidadã, de valores e princípios à luz dos direitos humanos e a democratização da política para uma transformação no atual cenário de desolação, pobreza e desigualdades sociais no qual a maioria da população alienável está inserida.

2.2 Plano nacional de educação em direitos humanos

Com as consequentes discussões a respeito dos Direitos Humanos, e a participação brasileira na Conferência Mundial dos Direitos Humanos, em 1993, a consolidação dos direitos passa a ser desenhada pelo governo, com a criação de um Comitê Nacional e posterior desenvolvimento da Programa Nacional de Direitos Humanos (PNDH) em 1995, além do Plano Nacional de Educação de Direitos Humanos (PNEDH), implementado em 2003. (VIOLA, 2010; UNESCO, 2017).

O PNEDH surge como um reforço ao PNDH em busca da maior incorporação da DUDH, formação de sujeitos de direitos e construção de uma cultura em Direitos Humanos. (BRASIL, 2006). Associado ao surgimento desta nova cultura, é esperado um grande avanço na democratização e a "construção de novas formas de organização social, apontando para a substantividade radical da democracia”. (CARBONARI, 2008, p. 15). Nessa ideologia, os direitos humanos estão interligados com a democracia de forma a elucidar a igualdade, alteridade e a visão popular acerca do poder e a necessidade constante de reivindicação à percepção de que algo está errado, a fim de evitar o congelamento intelectual e crítico da sociedade. (LEFORT, 1981). Além disso, o Plano Nacional de Educação em Direitos Humanos menciona uma concepção sobre direitos humanos, a qual "incorpora os conceitos de cidadania democrática, cidadania ativa e cidadania planetária, por sua vez inspiradas em valores humanistas e embasadas nos princípios da liberdade, da igualdade, da equidade e da diversidade". (BRASIL, 2007, p. 23).

A partir da implementação do $\mathrm{PNEDH}$, a educação básica adota a temática de Educação em Direitos Humanos dentro do currículo escolar a fim de atingir estudantes do ensino fundamental e médio. (TAVARES, 2010). Por meio desse sistema, o Plano visa, de forma gradual, consolidar seus princípios norteadores de

[...] desenvolver uma cultura de direitos humanos; assegurar que os objetivos e práticas a serem adotadas sejam coerentes com os valores e princípios da educação em direitos humanos; estruturar-se na diversidade cultural e ambiental, garantindo a cidadania, o acesso ao ensino, permanência e 
conclusão; [...]ser um dos eixos fundamentais da educação básica e permear o currículo, a formação inicial e continuada dos profissionais da educação, o projeto político pedagógico da escola e os materiais didático-pedagógicos, o modelo de gestão e a avaliação; [...] ser orientada para a educação em direitos humanos, assegurando seu caráter transversal e a relação dialógica entre os diversos atores sociais. (BRASIL, 2006, p. 32).

Com base nisso, o sistema educacional deve apresentar novas metodologias que sejam renováveis, flexíveis e participativas, estimulando o respeito à diversidade, promovendo a igualdade e liberdade por meio da efetivação dos direitos humanos dentro da educação básica formal. (TAVARES, 2010).

\subsection{Diretrizes nacionais para a educação em direitos humanos}

Com a evolução da sociedade e gradual incorporação dos Direitos Humanos nas mais diversas áreas, em 2012, o Ministério da Educação promulga as Diretrizes Nacionais para a Educação em Direitos Humanos com a finalidade de implantar, de forma mais aprofundada, os Direitos Humanos no âmbito educacional. Tal documento foi elaborado com base em diversos outros: Declaração Universal dos Direitos Humanos, Declaração das Nações Unidas sobre a Educação e Formação em Direitos Humanos, Constituição Federal de 1988, Lei de Diretrizes e Bases da Educação Nacional, Programa Mundial de Educação em Direitos Humanos, Programa Nacional de Direitos Humanos e Plano Nacional de Educação em Direitos Humanos, já citado e descrito anteriormente. (BRASIL, 2012a). As diretrizes são compostas por 12 artigos que contemplam as ideias veiculadas nos documentos embasadores de forma a orientar mudanças nas propostas curriculares estaduais em favor da efetivação dos Direitos Humanos nas redes de ensino.

Na concepção deste documento, a Educação em Direitos Humanos é tida como o "uso de concepções e práticas educativas fundadas nos Direitos Humanos e em seus processos de promoção, proteção, defesa e aplicação na vida cotidiana e cidadã de sujeitos de direitos e de responsabilidades individuais e coletivas". (BRASIL, 2012a, p. 1). Além disso, a Educação em Direitos Humanos objetiva formar sujeitos de direitos com consciência cidadã, aptos à convivência em sociedade e ao exercício dos Direitos Humanos nos mais diversos âmbitos que a compõe. (BRASIL, 2012a). Por meio desse documento, uma nova era se inicia para a educação a nível nacional, rebuscada nos conceitos de igualdade de direitos, participação estudantil, respeito às diversidades e formação de sujeitos de direitos de forma integral pois 
"quanto mais integral a formação dos sujeitos, maiores são as possibilidades de criação e transformação da sociedade". (SANTA CATARINA, 2014, p. 25).

A escola fornece uma educação básica formal e o desenvolvimento cognitivo e moral do ser humano sendo o ambiente ideal para o repasse de conhecimento acerca dos direitos e deveres do cidadão. O conhecimento histórico de lutas para o progresso da sociedade, a afirmação de valores, a construção da cidadania, um ambiente flexível e participativo e o fortalecimento da defesa dos Direitos Humanos, são dimensões que obrigatoriamente devem estar presentes nesse ambiente. Contudo, para maior efetividade quanto à consolidação da Educação em Direitos Humanos, a educação básica deve ser orientada no sentido da transversalidade, de forma a abordar a Educação em Direitos Humanos em todas as disciplinas escolares, sem distinção e em plenitude. (BRASIL, 2012a).

\subsection{Proposta curricular de Santa Catarina}

Para que a Educação em Direitos Humanos possa atingir de fato o sistema educacional é necessário o estabelecimento de parâmetros bem definidos e fundamentados, os quais podem ser encontrados, de forma clara e objetiva, dentro das Diretrizes Nacionais para a Educação em Direitos Humanos e da proposta curricular estadual. A Proposta Curricular de Santa Catarina (PCSC), teve sua primeira versão criada em 1988 e publicada em 1991, após a realização de amplas discussões entre educadores. Em 1996, verificou-se a necessidade de aprofundar o conteúdo da primeira versão a partir de um grupo multidisciplinar, o que resultou na publicação da segunda edição da proposta em 1998. Em 2003, inicia-se uma nova fase com a discussão a respeito da formação continuada dos professores conduzindo à criação de seis grupos temáticos multidisciplinares para elaboração de uma reformulação da proposta curricular, publicada em 2005. (SANTA CATARINA, 2005).

A partir de 2006, após publicação do documento que colocaria em prática o Plano Nacional de Educação em Direitos Humanos, um novo debate é erguido nacionalmente no tocante à formação de sujeitos de direitos e à consequente construção de uma cultura de direitos humanos tendo como viés a educação básica formal para atingir a educação informal. (BRASIL, 2006). As discussões se estenderam ao longo dos anos o que culminou com o estabelecimento de Diretrizes Nacionais para a Educação em Direitos Humanos em 2012. Neste documento é promulgada a obrigatoriedade da inclusão da Educação em Direitos Humanos dentro das redes de ensino a fim de promover um ensino mais flexível, participativo 
e democrático, com vistas à transformação social e com base nos princípios da "dignidade humana; igualdade de direitos; reconhecimento e valorização das diferenças e das diversidades; laicidade do Estado; democracia na educação; transversalidade, vivência e globalidade; e sustentabilidade socioambiental”. (BRASIL, 2012a, p. 1).

Neste cenário contemporâneo, torna-se evidente a imprescindibilidade da reformulação da proposta curricular do estado de Santa Catarina, tendo em vista as demandas sociais, educacionais, curriculares da rede de ensino do estado e Diretrizes Curriculares para a Educação Básica, onde contemplam a Educação em Direitos Humanos. (SANTA CATARINA, 2014). A nova PCSC, e também a mais recente, adotada atualmente nas escolas do estado, foi divulgada em 2014 e segue três pilares norteadores:

1) perspectiva de formação integral, referenciada numa concepção multidimensional de sujeito; 2) concepção de percurso formativo visando superar o etapismo escolar e a razão fragmentária que ainda predomina na organização curricular e 3) atenção à concepção de diversidade no reconhecimento das diferentes configurações identitárias e das novas modalidades da educação. (SANTA CATARINA, 2014, p. 20).

A proposta de 2014 foi elaborada por um grupo de professores e gestores da educação estadual, municipal, federal e privada. Essa atividade coletiva foi produzida "[...] de forma participativa e envolvendo profissionais tanto da Educação Básica como superior, suas modalidades e áreas do conhecimento, assim como de representações dos movimentos sociais". (SANTA CATARINA, 2014, p. 20).

O processo compreendeu um conjunto de reuniões preliminares com a equipe técnica da Secretaria de Educação/SC e o grupo de produção, composto por professores das diversas áreas do conhecimento e de seus respectivos componentes curriculares e especialistas, seguido de cinco seminários presenciais mensais, contemplados de março a julho de 2014 . (SANTA CATARINA, 2014). Esses professores foram selecionados mediante a um processo seletivo, via edital, sendo contemplados aproximadamente 200 profissionais das diferentes regiões do Estado, modalidades de educação, redes e níveis de ensino e etapas da Educação Básica.

Simultaneamente aos trabalhos do grupo de produção, "foi desenvolvida e disponibilizada uma página interativa na internet para que mais professores das redes de ensino pudessem, à distância, acompanhar o trabalho do grupo de produção e contribuir no processo de elaboração dos textos”. (SANTA CATARNIA, 2014, p. 21). Nesse sentido, foi disponibilizado na plataforma salas interativas distribuídas em cinco áreas, como Ciências da 
Natureza e Matemática; de Ciências Humanas; de Diversidades; de Educação Infantil e Séries

Iniciais do Ensino Fundamental; e de Linguagens. (SANTA CATARNIA, 2014). É importante mensurar que houveram aproximadamente 8.000 professores participantes. $\mathrm{Na}$ referida página, "os participantes tiveram acesso às webconferências, aos textos anteriores da Proposta Curricular de Santa Catarina, a fóruns e textos complementares que compuseram a totalidade do material de apoio para este movimento de atualização". (SANTA CATARINA, 2014, p. 21).

O presente documento está estruturado em duas partes: a primeira é dedicada a apresentar o resultado das discussões sobre "Educação Básica e Formação Integral”, p. 23-90, e inclui o debate em torno dos conceitos de percurso formativo e diversidade. Na segunda parte, destacam-se as "Contribuições das áreas do conhecimento para a educação básica e a formação integral: Linguagens, Ciências Humanas e Ciências da Natureza e Matemática”, p. 91-172. (SANTA CATARINA, 2014).

\section{MATERIAL E MÉTODOS}

A metodologia adotada é de cunho exploratório, qualitativo e documental em consonância com a análise de conteúdo de Laurence Bardin. A análise de conteúdo, segundo Bardin (2016, p. 44), é "um conjunto de técnicas de análise das comunicações que utiliza procedimentos sistemáticos e objetivos de descrição do conteúdo das mensagens". Neste sentido, sabe-se que a intenção da análise de conteúdo é a "inferência de conhecimentos relativos às condições de produção (ou, eventualmente, de recepção), inferência esta que recorre a indicadores (quantitativos ou não)”. (BARDIN, 2016, p. 44).

Esta pesquisa decorreu de 5 etapas:

$1^{\text {a }}$ etapa: contemplou uma pré-análise, a organização dos documentos da Proposta Curricular de Santa Catarina (PCSC) de 2014 e da Resolução CNE/CP n 1 de 30 de maio de 2012 que estabelece as Diretrizes Nacionais para a Educação em Direitos Humanos (DNEDH), uma leitura flutuante para obter contato com os documentos, primeiras impressões e orientações e a formulação do objetivo para nortear a pesquisa;

$\mathbf{2}^{\mathbf{a}}$ etapa: realização da definição das categorias de análise a partir de elementos lexicais relacionados a Educação em Direitos Humanos, palavras, sentidos ou frases associadas. 
$3^{\text {a }}$ etapa: exploração do material documental por meio da leitura da PCSC, na qual as categorias foram sendo identificadas e correlacionadas aos artigos das DNEDH, visando comparar enunciados e ações entre si, no intuito de averiguar possíveis unificações.

$4^{\text {a }}$ etapa: tratamento desses resultados, mediante recorte dos textos identificados e transferência para uma tabela de associação de idéias por intermédio da qual inferências foram obtidas.

$\mathbf{5}^{\mathbf{a}}$ etapa: retorno ao referencial teórico para embasar as análises e dar significação à interpretação.

O procedimento de análise lexical decorreu do confrontamento dos recortes teóricos obtidos a partir da PCSC e DNEDH para construção das considerações finais.

\section{ANÁLISE DOS DADOS E RESULTADOS}

Inicialmente foi desconsiderado da análise o artigo $13^{\circ}$ das Diretrizes Nacionais para a Educação em Direitos Humanos, por mencionar que "esta resolução entrará em vigor na data de sua publicação". (BRASIL, 2012a, p. 3). Nesse sentido, trabalhou-se então com os demais doze artigos, associados aos recortes dos textos contendo elementos em comum encontrados no teor da Proposta Curricular de Santa Catarina. O resultado foi muito significativo, totalizando em $75 \%$ da implementação da resolução na PCSC, contidos em nove artigos, conforme demonstra a Tabela 1.

Tabela 1 - Tabela de Associação de Ideias da PCSC e DNEDH

\begin{tabular}{clcc}
\hline & Proposta Curricular de Santa Catarina (2014) & DNEDH & \% \\
\hline 1 menção & p. 20 & $1^{\circ}$ artigo & $2 \%$ \\
5 menções & p. $26-27,32,55,68$ e 136 & $2^{\circ}$ artigo & $9,5 \%$ \\
31 menções & p. $53-54,54,55,55,57,57,57,58,59,60,60,61,61,62,62-63$, & $3^{\circ}$ artigo & $59,5 \%$ \\
& $63,63,63,65,65,69,84,85,87,87-88,88,88,88-89,89,90$ e & \\
& 172. & $4^{\circ}$ artigo & $11,5 \%$ \\
6 menções & p. $25,25,25,26,26$ e 27 & $5^{\circ}$ artigo & $5,5 \%$ \\
3 menções & p. $26,26-27$ e 27 & $6^{\circ}$ artigo & $4 \%$ \\
2 menções & p. 87 e 90 & $7^{\circ}$ artigo & $4 \%$ \\
2 menções & p. 25 e 26 & $8^{\circ}$ artigo & $2 \%$ \\
1 menção & p. 87 & $9^{\circ}$ artigo & 0 \\
0 & & $10^{\circ}$ artigo & 0 \\
0 & & $11^{\circ}$ artigo & $2 \%$ \\
1 menção & p. 88 & $1^{\circ}$ artigo & 0 \\
0 & & &
\end{tabular}

Fonte: As autoras, 2017.

$\mathrm{O}$ artigo $3^{\circ}$ foi o mais mencionado na PCSC, com 59,5\% de citações, demonstrando maior preocupação dos autores com os princípios da Educação em Direitos Humanos. Tais 
princípios visam a busca pelo respeito à dignidade humana, à igualdade de direitos, à diversidade cultural, ao reconhecimento e valorização das diferenças, à liberdade de crenças e à sustentabilidade socioambiental, para que o sujeito possa vivenciar melhorias na qualidade das relações interpessoais que são construídas socialmente e efetivar os direitos humanos. Todavia, nas palavras de Gomes (2007, p. 30), acredita-se que incorporar a diversidade no currículo, tomando-a como um eixo principal, pode constituir-se de um direito assegurado a todos, independentemente de suas condições, sendo que "se a convivência com a diferença já é salutar para a reeducação do nosso olhar, dos nossos sentidos, da nossa visão de mundo, quanto mais o aprendizado do imperativo ético que esse processo nos traz". (GOMES, 2007, p. 30).

Nesta perspectiva, Santos (2006, p. 316) complementa que "temos o direito de ser iguais quando a nossa diferença nos inferioriza; e temos o direito de ser diferentes quando a nossa igualdade nos descaracteriza". Da mesma forma, a diferença pode estar relacionada com o outro desigual, no reconhecimento e respeito à sua dignidade humana e aos seus direitos, além de se preocupar com o meio ambiente.

Alguns artigos não foram citados ou abordados na proposta, como é o caso do $9^{\circ}, 10^{\circ} \mathrm{e}$ $12^{\circ}$. O primeiro desses menciona a EDH na formação inicial e continuada de todos os profissionais das diferentes áreas do conhecimento, enquanto outro, respectivamente, ressalta que o fomento e a divulgação de estudos bem-sucedidos na área de EDH deverão ser feitos nos sistemas de ensino e nas instituições. Contudo, o artigo $12^{\circ}$ trata das Instituições de Educação Superior as quais "estimularão ações de extensão voltadas para a promoção de Direitos Humanos, em diálogo com os segmentos sociais em situação de exclusão social e violação de direitos, assim como com os movimentos sociais e a gestão pública". (BRASIL, 2012a, p. 3).

Observou-se também na primeira parte do documento da PCSC, intitulada 'Educação Básica e Formação Integral', a qual inclui o debate em torno dos conceitos de percurso formativo e diversidade, que esta foi a que mais obteve correlação com a resolução em estudo, resultando em 96\% das menções, contemplados historicamente pela compreensão de mundo, conhecimentos e saberes a serem integrados na contemporaneidade. Logo, a segunda parte da proposta curricular, denominada 'Contribuições das áreas do conhecimento para a educação básica e a formação integral: Linguagens, Ciências Humanas e Ciências da Natureza e Matemática', alcançou apenas $4 \%$ da analogia. Este último resultado, pode estar relacionado a fatores mais específicos das áreas do conhecimento, como esclarecimentos sobre a 
necessidade de "superar a fragmentação disciplinar, [...] a compreensão de que qualquer agrupamento é feito sob critérios que podem (e devem) ser criticados e colocados em suspensão em qualquer discussão". (SANTA CATARINA, 2014, p. 93), além de articular os componentes curriculares de cada área.

Seguem abaixo, os recortes da análise das associações lexicais entre as Diretrizes Nacionais para a Educação em Direitos Humanos (2012) e a Proposta Curricular de Santa Catarina (2014).

Artigo $1^{\circ}$ A presente Resolução estabelece as Diretrizes Nacionais para a Educação em Direitos Humanos $(\mathrm{EDH})$ a serem observadas pelos sistemas de ensino e suas instituições.

Nos últimos anos, novas demandas sociais, educacionais e curriculares vêm induzindo a (re)formulação de Diretrizes Curriculares Nacionais para a Educação Básica ${ }^{1}$. A atualização da Proposta Curricular torna-se, assim, necessária em face do conjunto dessas diretrizes e de demandas das redes de ensino do Estado de Santa Catarina.

Nota de rodapé:

${ }^{1}$ Trata-se de Diretrizes Curriculares para: Educação Infantil, Ensino Fundamental, Ensino Médio, Educação Profissional Técnica de Nível Médio, Educação de Jovens e Adultos, Educação Especial, Educação do Campo, Educação Ambiental, Educação para os Direitos Humanos, ... (p. 20)

Artigo $2^{\circ}$ A Educação em Direitos Humanos, um dos eixos fundamentais do direito à educação, refere-se ao uso de concepções e práticas educativas fundadas nos Direitos Humanos e em seus processos de promoção, proteção, defesa e aplicação na vida cotidiana e cidadã de sujeitos de direitos e de responsabilidades individuais e coletivas.

$\S 1^{\circ}$ Os Direitos Humanos, internacionalmente reconhecidos como um conjunto de direitos civis, políticos, sociais, econômicos, culturais e ambientais, sejam eles individuais, coletivos, transindividuais ou difusos, referem-se à necessidade de igualdade e de defesa da dignidade humana.

$\S 2^{\circ}$ Aos sistemas de ensino e suas instituições cabe a efetivação da Educação em Direitos Humanos, implicando a adoção sistemática dessas diretrizes por todos(as) os(as) envolvidos(as) nos processos educacionais.

Em termos de aporte teórico-epistemológico, a perspectiva histórico-cultural oferece um arcabouço dos mais amplos para a compreensão da Formação Integral e para a reflexão sobre ela. O ponto de partida é o sujeito na/da formação, compreendido como ser social e histórico de direito subjetivo à aprendizagem e ao desenvolvimento em sua concepção ampla. Sujeito que, nas experiências de vida e nas relações com outros sujeitos, com a natureza e com as estruturas e instituições sociais, faz apropriações de mundo mediadas por diferentes linguagens. (p. 26-27)

Desta forma, convidamos os professores a ... (3) refletir acerca da função social da escola e dos direitos sociais, entre eles, em se tratando especificamente da escola, o direito de aprender e desenvolver-se; (p. 32)

Os direitos civis, políticos e sociais focalizam, pois, direta ou indiretamente, o tratamento igualitário, e estão em consonância com a temática da igualdade social. Já o direito à diferença busca garantir que, em nome da igualdade, não se desconsiderem as diferenças culturais e individuais. Em decorrência, espera-se que a escola esteja atenta a essas diferenças, a fim de que em torno delas não se construam mecanismos de exclusão que impossibilitem a concretização do direito à educação, que é um direito de todos. (p. 55)

Para tanto, é preciso reconhecer que todos os sujeitos da escola são detentores de identidade, de história, de personalidade cultural e étnica, que possuem conteúdos e saberes e que são sujeitos de direitos, isto é, que têm o direito de ter direitos. (p. 68)

Área das Linguagens: [...] práticas devem ser abordadas levando em consideração temas comuns a todas elas, tais como: a saúde, o lazer e a recreação, a competição/rendimento, e, ainda, entende-se que é fundamental estabelecer relações entre a Educação Física e a diversidade, que inclui as pessoas com deficiência, a diversidade étnico-racial, a diversidade sexual, a educação do campo e a relação campo-cidade, a questão ambiental, a prevenção e proteção e os direitos humanos. (136) 
Artigo $3^{\circ}$ A Educação em Direitos Humanos, com a finalidade de promover a educação para a mudança e a transformação social, fundamenta-se nos seguintes princípios:

I - dignidade humana;

II - igualdade de direitos;

III - reconhecimento e valorização das diferenças e das diversidades;

IV - laicidade do Estado;

V - democracia na educação;

VI - transversalidade, vivência e globalidade; e

VII - sustentabilidade socioambiental.

[...] ao longo das últimas duas décadas, no Brasil, políticas públicas em educação vêm sendo firmadas com o intuito de reduzir as desigualdades no percurso educacional entre todos os segmentos sociais. [...] a Educação Básica como um direito desponta ancorada no princípio do bem comum e no respeito à diversidade. [...] $\mathrm{O}$ movimento de Atualização da Proposta Curricular do Estado de Santa Catarina exprime a necessidade de uma Educação Básica que reconheça e assuma a diversidade como um princípio formativo e fundante do currículo escolar. (p. 53-54)

A diversidade está relacionada com as aspirações dos grupos humanos e das pessoas de viver em liberdade e no exercício de sua autodeterminação, como também à aspiração da vida em democracia e à necessidade de vivenciar coletivamente as realidades sociais que são múltiplas e de lutar pelo reconhecimento dos direitos humanos e a respeitá-los. Portanto, a valorização das diferenças étnicas e culturais, por exemplo, não significa aderir aos valores do outro, mas respeitá-lo como expressão da diversidade de todo ser humano, sem qualquer discriminação. (p. 54)

$\mathrm{O}$ direito à diferença, no espaço público, significa não apenas a tolerância com o outro, aquele que é diferente de nós, mas implica a revisão do conjunto dos padrões sociais de relações na sociedade, exigindo uma mudança que afeta a todos. Isso significa que a questão da identidade e da diferença tem caráter político. $\mathrm{O}$ direito à diferença se manifesta por meio da afirmação dos direitos de crianças, mulheres, jovens, idosos, homossexuais, negros, quilombolas, indígenas, pessoas com deficiência, entre outros, que, para de fato se efetivarem, necessitam ser socialmente reconhecidos. Trata-se, portanto, de compreender como as identidades e as diferenças são construídas e que mecanismos e instituições estão implicados na construção das identidades, determinando a valorização de uns e o desprestígio de outros. (p. 55)

Os direitos civis, políticos e sociais focalizam, pois, direta ou indiretamente, o tratamento igualitário, e estão em consonância com a temática da igualdade social. Já o direito à diferença busca garantir que, em nome da igualdade, não se desconsiderem as diferenças culturais e individuais. Em decorrência, espera-se que a escola esteja atenta a essas diferenças, a fim de que em torno delas não se construam mecanismos de exclusão que impossibilitem a concretização do direito à educação, que é um direito de todos. (p. 55)

Assim, podemos afirmar que os sujeitos da diversidade somos todos nós, mas há que destacar os grupos que vivenciaram processos de preconceito e discriminação, principalmente, no percurso formativo. É para aqueles que a Lei de Diretrizes e Bases da Educação Nacional (Lei no 9394/1996) diz ser obrigatório o ensino de seus conteúdos históricos nas escolas, [...] para aqueles que se reconstroem em seus direitos, em suas identidades, nos movimentos de direitos humanos, nas relações de gênero e na diversidade sexual. (p. 57)

Para combater as inúmeras formas de discriminação ainda existentes, faz-se necessário combinar os pactos nacionais e internacionais de proteção aos direitos humanos com medidas e políticas que acelerem a construção de uma cultura de direitos em que se reconheçam as diferentes identidades, como processo de inclusão de grupos socialmente vulneráveis. (p. 57)

[...] considerando as Diretrizes Curriculares Nacionais para Educação e Direitos Humanos, estão em discussão: a educação para as relações de gênero; a educação para a diversidade sexual (orientação sexual e identidade de gênero); a educação e prevenção; a educação ambiental formal; a educação das relações étnico-raciais; e as modalidades de ensino: a educação especial; a educação escolar indígena; a educação do campo e a educação escolar quilombola. (p. 57)

Educação para as Relações de Gênero, no âmbito da Educação Básica, reconhece esta categoria identitária como importante na vida das pessoas (sejam elas crianças, jovens, adultos e idosos). (p. 58)

Uma Educação para Diversidade Sexual reconhece que, nos sujeitos LGBT, a identidade de gênero assume ainda mais importância na medida em que estão sujeitos a discriminações homofóbicas, lesbofóbicas, transfóbicas e exclusão social. (p. 59)

A laicidade do Estado, bem como a laicidade dos currículos escolares é fundamental para que a escola discuta as pluralidades, em todas as suas nuances e desdobramentos, como produto da ação humana e da cultura, a partir do conhecimento científico. (p. 60)

A Proposta Curricular de Santa Catarina centra-se no pressuposto de que o direito à educação para todos deve ser garantido por meio da efetivação de políticas contra formas associadas de exclusão, em especial aquelas 
motivadas por preconceito e discriminação de natureza étnico-racial, de orientação sexual ou de identidade de gênero, bem como, qualquer outra decorrente de conteúdos ou condutas incompatíveis com a dignidade humana. (p. 60)

O contexto atual requer o reconhecimento dos diversos arranjos (organizações, configurações) familiares da contemporaneidade, o que possibilitará a reflexão e problematização do conceito de família, ampliando os recursos para discutir gênero, diversidade sexual e direitos humanos. (p. 61)

Outra atualização necessária é enfatizar o caráter da coeducação permanente, em toda a Educação Básica, em todas as áreas e em todos os componentes curriculares a fim de que a igualdade nas relações de gênero se torne uma realidade na Formação Integral de nossas crianças e jovens. (p. 61)

A implementação da Educação e Prevenção tem a escola como um espaço privilegiado onde as crianças, adolescentes, adultos e idosos ampliam os saberes científicos, a convivência, as inter-relações com e entre sujeitos da diversidade(suas diferenças, suas vivências, seus valores e ética). Portanto, a educação deve ser também um espaço de justiça social, cidadania e de respeito aos direitos humanos. Importante, também, destacar que o Estatuto do Idoso (Lei $n^{\circ} 10.741$, de $1^{\circ}$ de outubro de 2003). (p. 62)

Ver a diversidade como princípio formativo requer minimizar as vulnerabilidades a que estão expostos, com base no respeito à diversidade sexual, de gênero, às etnias, às religiões, às culturas, evitando toda forma de preconceito, de violência, de relações de poder, que viole os direitos humanos. (p. 62-63)

Entre os sujeitos da escola e a sua relação com a natureza destaca-se a Educação Ambiental Formal (EAF). A educação preconiza desempenhar alguma função no sujeito nos contextos sociais, econômicos, culturais e políticos, com o propósito de mudar comportamentos para uma convivência sustentável na sociedade. (p. 63)

É importante que a escola, espaço de educação formal e de transformações sociais e coletivas, promova a construção de novas reflexões, atitudes, valores e mudanças culturais e sociais. Dessa forma, em consonância com os princípios da Educação Ambiental, buscam-se caminhos em que o sujeito conheça e se reconheça como parte integrante do meio no qual está inserido. (p. 63)

... a EAF é o processo por meio do qual o indivíduo e a coletividade constroem valores socioambientais, conhecimentos, habilidades, atitudes e competências para trabalhar, individual e coletivamente, tanto para evitar problemas ambientais e propor soluções para os existentes, como para a prevenção dos novos com vistas à manutenção da qualidade de vida e sua sustentabilidade (SANTA CATARINA, 2010; Capítulo 36 da Agenda 21). (p. 63)

$\mathrm{Na}$ gestão cuida e educa, a comunidade escolar poderá ter uma eficácia nas decisões de suas políticas quando valorizar a diversidade como mediadora através do diálogo, da democracia e da participação. (p. 65)

No quesito currículo, este é orientado por um Projeto Político Pedagógico que tem na valorização da diversidade a conexão entre a sala de aula, os saberes tradicionais e os conhecimentos científicos, além de incentivar a cidadania ambiental, visando à promoção da responsabilidade de todos para transformação local e global. (BRASIL, 2012b). (p. 65)

Para a Educação das Relações Étnico-Raciais, qualidade da educação não é observada somente pela dimensão da aprendizagem, mas também por outras, como aquelas que tratam da gestão e do currículo da escola, bem como das políticas e práticas para o respeito às diferenças. (p. 69)

A "diversidade como princípio formativo" repercute, necessariamente, nos conteúdos, na organização curricular, nos tempos e espaços escolares, no modelo de gestão e avaliação, nos materiais didáticos, na formação inicial e continuada, nas relações humanas, no sujeito da educação e no modelo de sociedade que a Escola ajuda a construir. (p. 84)

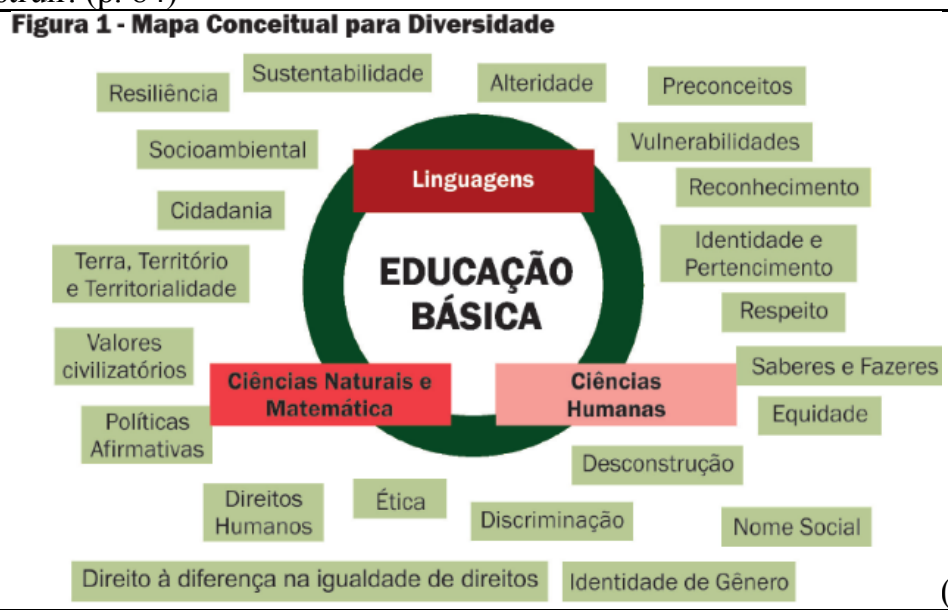

(p. 85)

... a escola deve garantir a reafirmação das diferenças individuais e coletivas a partir do senso de pertencimento identitário e no combate ao racismo, machismo, homofobia, xenofobia e a todas as formas de 
discriminação, violências e intolerâncias. (p. 87)

Realizar, fomentar e apoiar práticas e iniciativas, concursos e campanhas e outros eventos, divulgação de calendário de lutas LGBT, pesquisas e material didático, respeitando as especificidades, as diferentes linguagens (públicos e mídia), em formatos acessíveis e alternativos para maior visibilidade aos LGBT e promover o respeito e o reconhecimento das diferenças sexuais e identidades de gênero, entendendo os Direitos Humanos em toda a sua diversidade. (p. $87-88$ )

Sustentabilidade socioambiental: Neste princípio busca-se, por meio da gestão escolar, incentivar e promover propostas para um desenvolvimento sustentável considerando a diversidade da vida e das culturas para a sobrevivência de toda forma de vida, de hoje e das futuras gerações, principalmente no apoio à construção do Projeto Político Pedagógico (PPP) sustentado na convivência pública e na educação para a cidadania. Espera-se que a sustentabilidade socioambiental numa dimensão política da educação do cuidado com o sujeito, com o meio ambiente local, regional e global possa ser incorporada na realidade administrativo-pedagógica, social, estrutural e educacional. (p. 88)

Para acolher a diversidade o professor deve aceitar o desafio de novas experiências pedagógicas, assim como, "dialogar com" e conhecer outras propostas educativas, necessárias à compreensão das modalidades de educação específicas (Quilombola, do Campo, Ambiental, Especial, Indígena). Por exemplo, em relação às diferenças sexuais e de gênero, promover a elaboração, produção e distribuição de materiais de referência (obras científicas e literárias) e didático-pedagógicos, considerando especificidades [...]. (p. 88)

Laicidade do Estado e da escola pública catarinense: este é um princípio fundamental para assegurar a liberdade de expressão, a imparcialidade pedagógica, a valorização da cultura popular/histórica, garantindo o respeito à diversidade cultural religiosa, sem praticar qualquer forma de proselitismo (tentativa de converter à religião de interesse). (p. 88-89)

A igualdade de direitos não pode ser confundida com a inclusão das minorias aos costumes e tradições hegemônicos, ao contrário, ao considerar todos estudantes e suas diferenças humanas, tornam-se necessárias a revisão e a reorganização curricular que considere que o sujeito, como cidadão pleno e integral, tem o direito de frequentar uma escola voltada para a diversidade e na diversidade, que oportunize convivências e vivências reflexivas em diversos espaços, tempos e grupos culturais plurais. (p. 89)

Ao se discutir o PPP da escola é de fundamental importância considerar que a igualdade de direitos pressupõe o direito à diferença. Um exemplo de direito à igualdade na questão pedagógica é reconhecer a capacidade universal de aprender de todos como ponto de partida e compreender que existem diferenças nos processos de aprendizado dos estudantes. (p. 90)

Uma das prerrogativas desta Proposta é constituir-se em diretriz maior para que todos os sujeitos que integram as comunidades, escolares ou não, tenham respeitadas sua dignidade e direito de opção, seja ela voluntária ou ditada pela própria natureza humana. (p. 172)

Artigo $4^{0}$ A Educação em Direitos Humanos como processo sistemático e multidimensional, orientador da formação integral dos sujeitos de direitos, articula-se às seguintes dimensões:

I - apreensão de conhecimentos historicamente construídos sobre direitos humanos e a sua relação com os contextos internacional, nacional e local;

II - afirmação de valores, atitudes e práticas sociais que expressem a cultura dos direitos humanos em todos os espaços da sociedade;

III - formação de uma consciência cidadã capaz de se fazer presente em níveis cognitivo, social, cultural e político;

IV - desenvolvimento de processos metodológicos participativos e de construção coletiva, utilizando linguagens e materiais didáticos contextualizados; e

$\mathrm{V}$ - fortalecimento de práticas individuais e sociais que gerem ações e instrumentos em favor da promoção, da proteção e da defesa dos direitos humanos, bem como da reparação das diferentes formas de violação de direitos.

A Formação Integral tem assumido papel cada vez mais central no debate sobre os pressupostos e finalidades da Educação Básica no Brasil. Como concepção de formação e como projeto educacional, ela forma parte da histórica luta pela emancipação humana. Quanto mais integral a formação dos sujeitos, maiores são as possibilidades de criação e transformação da sociedade. (p. 25)

A busca pela Formação Integral é, portanto, parte da experiência humana na qual a escolarização vai ocupando lugar central, e a educação é, nesse sentido, expressão do desejo e do direito humano fundamental. $O$ currículo, por sua vez, entendido como constituinte e constitutivo do percurso formativo, torna-se expressão material desse direito e o sujeito, o sentido último e finalidade principal da formação. (p. 25)

Assim, a formação integral continua sendo um dos mais importantes e antigos projetos humanos. A educação formal, com a adjetivação "integral", constitui uma luta contemporânea que representa uma alternativa para o 
avanço da sociedade em relação aos atuais limites da escola. Mais do que a noção de educação integral, o que está posto na atualidade é como a escola enquanto instituição social moderna pode cumprir a tarefa de promovêla. (p. 25)

Desta forma, quando tomamos a educação integral desde uma perspectiva histórico-cultural, torna-se evidente a busca por uma formação que considere a emancipação, a autonomia e a liberdade como pressupostos para uma cidadania ativa e crítica, que possibilite o desenvolvimento humano pleno e a apropriação crítica do conhecimento e da cultura. (p. 26)

Uma formação mais integral do cidadão supõe considerar e reconhecer o ser humano como sujeito que produz, por meio do trabalho, as condições de (re)produção da vida, modificando os lugares e os territórios de viver, revelando relações sociais, políticas, econômicas, culturais e socioambientais. (p. 26)

Esse sujeito tem o direito a uma formação que tome como parâmetro todas as dimensões que constituem o humano. Uma formação que reconheça e ensine a reconhecer o direito a diferença, a diversidade cultural e identitária; que contemple as dimensões ética, estética, política, espiritual, socioambiental, técnica e profissional. (p. 27)

Artigo $5^{\mathbf{0}}$ A Educação em Direitos Humanos tem como objetivo central a formação para a vida e para a convivência, no exercício cotidiano dos Direitos Humanos como forma de vida e de organização social, política, econômica e cultural nos níveis regionais, nacionais e planetário.

$\S 1^{\circ}$ Este objetivo deverá orientar os sistemas de ensino e suas instituições no que se refere ao planejamento e ao desenvolvimento de ações de Educação em Direitos Humanos adequadas às necessidades, às características biopsicossociais e culturais dos diferentes sujeitos e seus contextos.

$\S 2^{\circ}$ Os Conselhos de Educação definirão estratégias de acompanhamento das ações de Educação em Direitos Humanos.

Uma formação mais integral do cidadão supõe considerar e reconhecer o ser humano como sujeito que produz, por meio do trabalho, as condições de (re)produção da vida, modificando os lugares e os territórios de viver, revelando relações sociais, políticas, econômicas, culturais e socioambientais. (p. 26)

Em termos de aporte teórico-epistemológico, a perspectiva histórico-cultural oferece um arcabouço dos mais amplos para a compreensão da Formação Integral e para a reflexão sobre ela. $\mathrm{O}$ ponto de partida é o sujeito na/da formação, compreendido como ser social e histórico de direito subjetivo à aprendizagem e ao desenvolvimento em sua concepção ampla. Sujeito que, nas experiências de vida e nas relações com outros sujeitos, com a natureza e com as estruturas e instituições sociais, faz apropriações de mundo mediadas por diferentes linguagens. (p. 26-27)

Esse sujeito tem o direito a uma formação que tome como parâmetro todas as dimensões que constituem o humano. Uma formação que reconheça e ensine a reconhecer o direito a diferença, a diversidade cultural e identitária; que contemple as dimensões ética, estética, política, espiritual, socioambiental, técnica e profissional. (p. 27)

Artigo $6^{0}$ A Educação em Direitos Humanos, de modo transversal, deverá ser considerada na construção dos Projetos Político-Pedagógicos (PPP); dos Regimentos Escolares; dos Planos de Desenvolvimento Institucionais (PDI); dos Programas Pedagógicos de Curso (PPC) das Instituições de Educação Superior; dos materiais didáticos e pedagógicos; do modelo de ensino, pesquisa e extensão; de gestão, bem como dos diferentes processos de avaliação.

Reorganizar a proposta político-pedagógica da escola de modo a inserir os direitos humanos e ambientais, tendo a diversidade como princípio formativo. (p.87)

Ao se discutir o PPP da escola é de fundamental importância considerar que a igualdade de direitos pressupõe o direito à diferença. Um exemplo de direito à igualdade na questão pedagógica é reconhecer a capacidade universal de aprender de todos como ponto de partida e compreender que existem diferenças nos processos de aprendizado dos estudantes. (p. 90)

Artigo $7^{\circ} \mathrm{A}$ inserção dos conhecimentos concernentes à Educação em Direitos Humanos na organização dos currículos da Educação Básica e da Educação Superior poderá ocorrer das seguintes formas:

I - pela transversalidade, por meio de temas relacionados aos Direitos Humanos e tratados interdisciplinarmente;

II - como um conteúdo específico de uma das disciplinas já existentes no currículo escolar; 
III - de maneira mista, ou seja, combinando transversalidade e disciplinaridade. Parágrafo único. Outras formas de inserção da Educação em Direitos Humanos poderão ainda ser admitidas na organização curricular das instituições educativas desde que observadas as especificidades dos níveis e modalidades da Educação Nacional.

A busca pela Formação Integral é, portanto, parte da experiência humana na qual a escolarização vai ocupando lugar central, e a educação é, nesse sentido, expressão do desejo e do direito humano fundamental. $O$ currículo, por sua vez, entendido como constituinte e constitutivo do percurso formativo, torna-se expressão material desse direito e o sujeito, o sentido último e finalidade principal da formação. (p. 25)

A grande questão em pauta, então, não é a validade ou a importância da formação integral como projeto educacional, mas a (re)configuração da escola e do currículo escolar necessária para sua materialização. Esse, sim, é o grande desafio educacional contemporâneo. A educação integral é, nesse sentido, uma estratégia histórica que visa desenvolver percursos formativos mais integrados, complexos e completos, que considerem a educabilidade humana em sua múltipla dimensionalidade. (p. 26)

Artigo $8^{\circ}$ A Educação em Direitos Humanos deverá orientar a formação inicial e continuada de todos(as) os(as) profissionais da educação, sendo componente curricular obrigatório nos cursos destinados a esses profissionais.

Investir na realização de cursos de formação continuada para professores, com a discussão dos conceitos do Mapa Conceitual para Diversidade da página 85, nos vários Componentes Curriculares. (p. 87)

Artigo 9 $9^{\circ}$ A Educação em Direitos Humanos deverá estar presente na formação inicial e continuada de todos(as) os(as) profissionais das diferentes áreas do conhecimento.

Artigo $\mathbf{1 0}^{\circ}$ Os sistemas de ensino e as instituições de pesquisa deverão fomentar e divulgar estudos e experiências bem-sucedidas realizados na área dos Direitos Humanos e da Educação em Direitos Humanos.

Artigo $1^{\circ}$ Os sistemas de ensino deverão criar políticas de produção de materiais didáticos e paradidáticos, tendo como princípios orientadores os Direitos Humanos e, por extensão, a Educação em Direitos Humanos.

Para acolher a diversidade o professor deve aceitar o desafio de novas experiências pedagógicas, assim como, “dialogar com” e conhecer outras propostas educativas, necessárias à compreensão das modalidades de educação específicas (Quilombola, do Campo, Ambiental, Especial, Indígena). Por exemplo, em relação às diferenças sexuais e de gênero, promover a elaboração, produção e distribuição de materiais de referência (obras científicas e literárias) e didático-pedagógicos, considerando especificidades [...] (p. 88)

Artigo $12^{\circ}$ As Instituições de Educação Superior estimularão ações de extensão voltadas para a promoção de Direitos Humanos, em diálogo com os segmentos sociais em situação de exclusão social e violação de direitos, assim como com os movimentos sociais e a gestão pública.

Artigo $1^{\circ}$ Esta Resolução entrará em vigor na data de sua publicação.

\section{CONSIDERAÇÕES FINAIS}

A proposta curricular mais recente de Santa Catarina aborda a Educação em Direitos Humanos em muitos trechos. Desconsiderado da análise o artigo $13^{\circ}$ das Diretrizes Nacionais para a Educação em Direitos Humanos e trabalhando com os demais doze artigos, dentro de um contexto generalizado, constata-se que a Proposta Curricular de Santa Catarina (PCSC), de 2014 contempla 75\% da implementação da resolução, fato que pode ser traduzido em um resultado importante e muito significativo com a demanda normativa. Neste sentido, apesar de 
inicialmente não encontrar na PCSC qualquer menção às Diretrizes Nacionais, o presente estudo deparou-se com resultados de uma proposta curricular organizada para atender a diversidade da clientela contemporânea, abrangendo a educação em direitos humanos, pautada na formação integral do sujeito com base no respeito, na promoção dos direitos e nas relações interpessoais de maneira transversal, preconizado nas DNEDH.

$\mathrm{O}$ artigo $3^{\circ}$ foi o mais mencionado na PCSC, com 59,5\%, demonstrando maior preocupação dos autores com os princípios da Educação em Direitos Humanos. Eles estão expressos no tocante à busca pelo respeito à dignidade humana, à igualdade de direitos, à diversidade cultural, ao reconhecimento e valorização das diferenças, à liberdade de crenças e à sustentabilidade socioambiental, para que o sujeito possa vivenciar melhorias na qualidade das relações interpessoais que são construídas socialmente e efetivar os direitos humanos.

A PCSC está orientada por outros documentos nacionais que possivelmente auxiliaram na inclusão da maioria dos artigos das Diretrizes Nacionais para a Educação em Direitos Humanos, além de assegurar o direito de todos à educação, como: Constituição Federal/1988,Lei de Diretrizes e Bases da Educação Nacional/ 1996, Diretrizes Curriculares Nacionais para a Educação das Relações Étnico-Raciais e para o ensino de História e Cultura Afro-brasileira e Africana/ 2004, Política Nacional de Educação Especial na Perspectiva da Educação Inclusiva/ 2008, Programa Nacional de Direitos Humanos (PNDH-3)/2010, Diretrizes Curriculares Nacionais Gerais para a Educação Básica/2010, Diretrizes Curriculares Nacionais para a Educação Básica/2010 (onde contemplam a Educação em Direitos Humanos), Diretrizes Curriculares Nacionais para a Educação Ambiental/ 2012, Diretrizes Curriculares Nacionais para a Educação Escolar Indígena na Educação Básica/ 2012, Diretrizes curriculares nacionais gerais para a educação básica/ 2013, dentre outros. Sendo assim, constatou-se que foi uma falha humana não mencionar a Resolução $\mathrm{n}^{\mathbf{0}} 1$, de 30 de maio de 2012 na elaboração da última Proposta Curricular de Santa Catarina.

Os Direitos Humanos têm norteado a sociedade por meio de seus princípios organizativos quanto à igualdade de direitos, o respeito à diversidade, a democratização e o estabelecimento da paz mundial. Nesse cenário, a educação é colocada como um instrumento de efetivação dos direitos dentro do ambiente escolar. Para tal efetivação, da PCSC e das DNEDH, sugere-se aos profissionais da educação trabalhem temas envolvendo práticas para vivenciar uma educação em direitos humanos na formação inicial e continuada, visando construir uma cultura em direitos humanos nas escolas e, consequentemente, dentro da sociedade. Nesse sentido, acredita-se que é por meio dos estudantes, que a educação formal 
pode ser convertida em educação informal, de forma a gerar uma rede de conhecimento em direitos humanos e sua aplicabilidade, numa tentativa de construir a tão sonhada cultura de direitos humanos. Além disso, há a necessidade de esforço individual e coletivo para a mudança da realidade social, ou seja, no falar e viver o que acredito.

Um dos desafios na atualidade é aproximar o que propõe a Proposta Curricular de Santa Catarina das salas de aula e da gestão escolar, ou seja, dialogar diretamente com professores, coordenadores pedagógicos, especialistas e diretores, no sentido de contribuir com a reflexão sobre as atuais demandas educacionais em suas práticas pedagógicas. Tendo em vista que já se passaram alguns anos da elaboração da atual proposta, sugere-se, aos futuros pesquisadores, estudos exploratórios para verificar de que maneira ela está sendo colocada em prática.

\section{REFERÊNCIAS}

BARDIN, Laurence. Análise de Conteúdo. São Paulo: Edições 70, 2016.

BITTAR, Eduardo. Educação e Metodologia para Direitos Humanos. São Paulo, Quartier Latin, 2008.

BOBBIO, Norberto. A era dos direitos. São Paulo: Edunesp, 1998.

BRASIL. Comitê Nacional de Educação em Direitos Humanos. Plano Nacional de Educação em Direitos Humanos. Brasília: 2006.

BRASIL. Plano Nacional de Educação em Direitos Humanos.Comitê Nacional de Educação em Direitos Humanos. Brasília: Secretaria Especial dos Direitos Humanos, Ministério da Educação, Ministério da Justiça, UNESCO, 2007.

BRASIL. Resolução no 1 de 30 de maio de 2012, Estabelece Diretrizes Nacionais Para a Educação em Direitos Humanos. Diário Oficial da União, Brasília, no ${ }^{\mathrm{1}}$ 105, seção 1, p.48, 2012a.

BRASIL. Parecer CNE/CP $\mathbf{n}^{\mathbf{0}}$ 8/2012. Diretrizes Nacionais para a Educação em Direitos Humanos. Publicado no DOU, Seção 1, p. 33, 2012 b.

CANDAU, Vera Maria. Educação em Direitos Humanos: políticas curriculares. In: LOPES, Alice Casimiro; MACEDO, Elizabeth. Políticas de currículo em múltiplos contextos. São Paulo, Cortez, 2006.

CARBONARI, Paulo César. Direitos Humanos: reflexões para uma agenda abusada. In: BITTAR, Eduardo C.B.; TOSI, Giuseppe. Democracia e educação em direitos humanos numa época de insegurança. João Pessoa: Editora da Universidade, 2008. 
FORTES, Erasto. Apresentação. In: SILVA, Aida Maria Monteiro; TAVARES, Celma. Políticas e Fundamentos da Educação em Direitos Humanos. São Paulo: Cortez, 2010.

GOMES, Nilma Lino. Indagações sobre currículo: diversidade e currículo. Brasília: Ministério da Educação, Secretaria de Educação Básica, 2007.

LEFORT, Claude. A invenção democrática: os limites da dominação totalitária. São Paulo: Brasiliense, 1981.

SANTA CATARINA. Governo do Estado. Secretaria de Estado da Educação, Ciência e Tecnologia. Proposta curricular de Santa Catarina: Estudos Temáticos. Florianópolis: IOESC, 2005.

SANTA CATARINA. Governo do Estado. Secretaria de Estado da Educação. Proposta curricular de Santa Catarina: formação integral na educação básica. Estado de Santa Catarina, Secretaria de Estado da Educação, 2014.

SANTOS, Boaventura de Souza. A construção intercultural da igualdade e da diferença. In: SANTOS, B.S. A gramática do tempo. São Paulo: Cortez, p. 279-316, 2006.

SILVA, Aida Maria Monteiro. Direitos Humanos na Educação Básica: qual o significado? In: SILVA, Aida Maria Monteiro; TAVARES, Celma. Políticas e Fundamentos da Educação em Direitos Humanos. São Paulo: Cortez, 2010.

TOSI, Giuseppe. O que são esses "tais de direitos humanos"? In: FERREIRA, Lúcia de Fátima Guerra; ZENAIDE, Maria de Nazaré Tavares; PEQUENO, Marconi. Direitos Humanos na Educação Superior - Subsídios para a Educação em Direitos Humanos na Filosofia. João Pessoa: Editora Universitária da UFPB, 2010.

TAVARES, Celma; FILHO, Ivan Moraes. O direito Humano à Comunicação como base para uma educação cidadã. In: SILVA, Aida Maria Monteiro; TAVARES, Celma. Políticas e Fundamentos da Educação em Direitos Humanos. São Paulo: Cortez, 2010.

UN - UNITED NATIONS. Universal Declaration of Human Rights. Paris, 1948.

UNESCO. Evolução dos Direitos Humanos no Brasil. 2017. Disponível em: $<$ https://goo.gl/oUe2C8> Acesso em 26 jan. 2017.

VIOLA, Solon Eduardo Annes. Políticas de Educação em Direitos Humanos. In: SILVA, Aida Maria Monteiro; TAVARES, Celma. Políticas e Fundamentos da Educação em Direitos Humanos. São Paulo: Cortez, 2010. 